\title{
The Riemerella anatipestifer M949_RS01035 gene is involved in bacterial lipopolysaccharide biosynthesis
}

\author{
Yafeng Dou', Guijing Yu' ${ }^{1}$, Xiaolan Wang ${ }^{1}$, Shaohui Wang ${ }^{1}$, Tao Li', Mingxing Tian' ${ }^{1}$, Jingjing Qi ${ }^{1}$, Chan Ding ${ }^{1}$ \\ and Shengqing $Y u^{1,2^{*}}$
}

\begin{abstract}
In this study, the Riemerella anatipestifer mutant strain RA1062 was obtained by screening a random Tn4351 transposon mutant library. The mutant strain was unreactive with the anti-CH3 lipopolysaccharide monoclonal antibody, as demonstrated with an enzyme-linked immunosorbent assay, and its M949_RS01035 gene was inactivated. When cultured in trypticase soy broth, the late stage growth of the mutant RA1062 was significantly decreased. The mutant RA1062 was stained with crystal violet and presented a rough lipopolysaccharide phenotype, which differed from that of the wild-type strain $\mathrm{CH}$, suggesting that deletion of the M949_RS01035 gene resulted in defective lipopolysaccharide. Silver staining and Western blot analyses further confirmed that the RA1062 lipopolysaccharide had a deficiency in ladder-like binding pattern, as compared to lipopolysaccharide of the wild-type $\mathrm{CH} 3$ strain. In addition, the mutant RA1062 showed a higher susceptibility to complement-dependent killing, increased bacterial adhesion and invasion capacities to Vero cells, decreased blood bacterial loads, and attenuated virulence in infected ducks, when compared to the wild-type strain CH3. Moreover, RNA-Seq and real-time polymerase chain reaction analyses indicated that two genes were up-regulated and two were down-regulated in the mutant RA1062 genome. Furthermore, an animal protection experiment showed that immunization of ducks with inactivated RA1062 bacterin conferred effective crossprotection against challenge with the virulent $R$. anatipestifer serotypes 1,2 , and 10 . This study presents evidence that the M949_RS01035 gene is involved in bacterial phenotype, virulence, and gene regulation in $R$. anatipestifer. The mutant strain RA1062 could be used as a cross-protective vaccine candidate.
\end{abstract}

\section{Introduction}

Riemerella anatipestifer is a Gram-negative, non-motile, non-spore forming, and atrichous bacterium belonging to the family Flavobacteriaceae in the phylum Bacteroidetes [1]. R. anatipestifer has received considerable attention because infection of this bacterium cause major economic losses to the duck farming industry through high mortality, weight loss, and high treatment costs [2]. $R$. anatipestifer infection is a highly contagious disease that causes fibrinous pericarditis, airsacculitis, and perihepatitis in ducks [3]. To date, $21 R$. anatipestifer

\footnotetext{
*Correspondence: yus@shvri.ac.cn

1 Shanghai Veterinary Research Institute, Chinese Academy of Agricultural Sciences (CAAS), Shanghai, China

Full list of author information is available at the end of the article
}

serotypes have been identified worldwide; however, there is currently no effective cross-protection between different serotypes [4, 5]. In China, serotypes 1,2 , and 10 are responsible for most outbreaks of $R$. anatipestifer infection [6].

A variety of vaccines to protect farm ducks from $R$. anatipestifer infection have been investigated, including the chaperonin GroEL and inactivated bacterin [7, 8]. On the other hand, some potential virulence factors of $R$. anatipestifer have been described, including OmpA, VapD, and CAMP cohemolysin $[9,10]$.

As with other Gram-negative bacteria, lipopolysaccharide (LPS) is probably one of the most important virulence factors of $R$. anatipestifer. LPS is the major outer membrane component of Gram-negative bacteria and typically comprise three structure domains: lipid A,

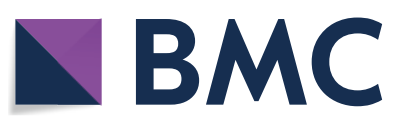

(c) The Author(s) 2018. This article is distributed under the terms of the Creative Commons Attribution 4.0 International License (http://creativecommons.org/licenses/by/4.0/), which permits unrestricted use, distribution, and reproduction in any medium, provided you give appropriate credit to the original author(s) and the source, provide a link to the Creative Commons license, and indicate if changes were made. The Creative Commons Public Domain Dedication waiver (http://creativecommons.org/ publicdomain/zero/1.0/) applies to the data made available in this article, unless otherwise stated. 
a core oligosaccharide, and a polysaccharide $\mathrm{O}$-antigen. The $\mathrm{O}$-antigen is composed of repeated sequences of three to six sugar residues and is also the most structurally variable cell surface constituent. Pathogenic bacterial $\mathrm{O}$-antigen plays important roles in avoiding phagocytosis and resisting the lytic action of the complement system [11-14]. The O-antigen has been also a basis for vaccine development against a variety of human pathogens, [15]. In several species of bacteria, such as Escherichia coli and Salmonella enterica, the genes involved in LPS biogenesis have been well characterized [16, 17]. In $R$. anatipestifer, five genes (AS87_04050, M949_1556, M949_1603, M949_1360 and M949_RS01915) associated with LPS synthesis have been characterized in our previous studies [18-22].

In this report, we described the identification of the $R$. anatipestifer mutant strain RA1062, in which the M949 RS01035 gene was disrupted by insertion of the Tn4351 transposon. Furthermore, the LPS phenotype, bacterial virulence, gene regulation, and the cross-protection of the mutant strain RA1062 were characterized.

\section{Materials and methods}

\section{Ethics statement}

The study protocol was approved by the Institutional Animal Care and Use Committee of Shanghai Veterinary Research Institute, the Chinese Academy of Agricultural Sciences (Approval No. Shvri-po-0072), and conducted in strict accordance with the recommendations outlined in the Guide for the Care and Use of Laboratory Animals. One-day old Cherry Valley ducks were obtained from Zhuang Hang Duck Farm (Shanghai, China) and housed in cages under a controlled temperature of $28-30^{\circ} \mathrm{C}$ with water and food ad libitum under biosafety conditions.

\section{Bacterial strains and growth conditions}

The bacterial strains and plasmids used in this study are listed in Table 3. The mutant strain RA1062 was derived from the wild-type (WT) $R$. anatipestifer strain $\mathrm{CH} 3$ (GenBank accession no. CP006649), which is a serotype 1 strain, by insertion of the Tn4351 plasmid. R. anatipestifer strains were grown on tryptic soy agar (TSA; Difco Laboratories, Franklin Lakes, NJ, USA) or in tryptic soy broth (TSB, Difco) at $37^{\circ} \mathrm{C}$ under an atmosphere of $5 \%$ $\mathrm{CO}_{2}$.

Escherichia coli strains were grown at $37{ }^{\circ} \mathrm{C}$ on LuriaBertani (LB) plates or in LB broth. When necessary, antibiotics were added to the medium at the following concentrations: kanamycin at $50 \mu \mathrm{g} / \mathrm{mL}$ and erythromycin at $0.5 \mu \mathrm{g} / \mathrm{mL}$ for the mutant strain RA1062, and chloramphenicol at $30 \mu \mathrm{g} / \mathrm{mL}$ for E. coli strain BW19851 (pEP4351).

\section{Indirect enzyme-linked immunosorbent assay (ELISA)}

An indirect ELISA was used to screen the Tn4351 insertion mutant library for strains with defective reactivity to the anti-CH3 LPS monoclonal antibody (mAb), as described previously [18]. Briefly, each well of a 96-well ELISA plate was coated with whole mutant cells at $10^{9}$ $\mathrm{CFU} /$ well in $50 \mu \mathrm{L}$ of carbonate-buffered saline $(\mathrm{pH}$ 9.6). The plates were heat-dried overnight at $55{ }^{\circ} \mathrm{C}$. After washing three times with phosphate-buffered saline (PBS) containing $0.05 \%$ Tween 20 (PBST), the plates were blocked with PBS-5\% skim milk at $37{ }^{\circ} \mathrm{C}$ for $2 \mathrm{~h}$, then incubated with anti-CH3 LPS mAb, as the primary antibody, and horseradish peroxidase-conjugated anti-mouse immunoglobulin G (IgG; Tiangen Biotech (Beijing) Co., Ltd., Beijing, China), as the secondary antibody. The reaction was visualized by adding $100 \mu \mathrm{L}$ of 3,30,5,50-tetramethyl benzidine (Tiangen) and stopped by the addition of $50 \mu \mathrm{L}$ of $2 \mathrm{M} \mathrm{H}_{2} \mathrm{SO}_{4}$. The resulting optical density at $450 \mathrm{~nm}\left(\mathrm{OD}_{450}\right)$ was measured using a plate reader (Synergy 2; BioTek Instruments, Inc., Winooski, VT, USA). The WT strain $\mathrm{CH} 3$ was used as a positive coating control. The mutants with its coating wells presenting an $\mathrm{OD}_{450}$ reading more than 2.1 times lower than that of the positive coating control were collected for further characterization. All mutants were screened in triplicate.

\section{Characterization of the mutant strain RA1062}

The WT strain $\mathrm{CH} 3$ and the mutant strain RA1062 were identified by polymerase chain reaction (PCR) analysis with the primers $16 \mathrm{~S}$ rRNA F/16S rRNA R, Erm-F/ Erm-R, and RA1062-F/RA1062-R (Table 1). Bacterial mutants were constructed by transposon mutagenesis as described previously [23], with modifications. The $E$. coli BW19851 with the plasmid pEP4351 was used as the donor strain and $R$. anatipestifer $\mathrm{CH} 3$ as the recipient. For bacterial mating, both donor and recipient bacteria were grown to mid-logarithmic phase, mixed at a bacterial colony forming units (CFU) ratio of $1: 2$ and centrifuged at $5500 \times g$ for $10 \mathrm{~min}$. The bacterial pellet was washed and re-suspended with $10 \mathrm{mM} \mathrm{MgSO}_{4}$, and filtered through a Millipore membrane, which was then placed face up on TSA with $1 \mu \mathrm{g} / \mathrm{mL}$ erythromycin and $50 \mu \mathrm{g} / \mathrm{mL}$ kanamycin. Following overnight incubation at $30^{\circ} \mathrm{C}$, the bacteria were scraped off the filter, resuspended in $5 \mathrm{~mL} 10 \mathrm{mM} \mathrm{MgSO}_{4}$, and spread on TSA containing erythromycin and kanamycin to select for transconjugants. To confirm one insertion of the Tn4351 transposon in the mutant strain RA1062, Southern blot analysis was conducted as previously described [6]. Briefly, genomic DNA of the mutant strain RA1062 was extracted using the TIANamp Bacteria DNA kit (Tiangen), digested

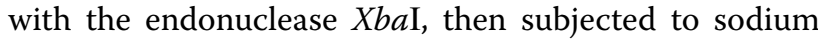


Table 1 Strains, plasmids, and primers used in this study

\begin{tabular}{|c|c|c|}
\hline Strains, plasmids or primers & Characteristics & Source or references \\
\hline \multicolumn{3}{|l|}{ Strains } \\
\hline $\mathrm{CH} 3$ & Riemerella anatipestifer serotype 1 strain & [6] \\
\hline RA1062 & $\begin{array}{l}\text { Tn4351 insertion mutant of Riemerella. anatipestifer CH3, M949_ } \\
\text { RS01035:: Tn }\end{array}$ & This study \\
\hline BW19851(pEP4351) & Plasmid pEP4351 in BW19851, CmR & [6] \\
\hline WJ4 & R. anatipestifer WT strain, serotype 1 & [6] \\
\hline Yb2 & R. anatipestifer WT strain, serotype 2 & [6] \\
\hline $\mathrm{HXb2}$ & R. anatipestifer WT strain, serotype 10 & [6] \\
\hline \multicolumn{3}{|l|}{ Primers } \\
\hline 16S rRNA F & 5'-GAGCGGTAGAGTATCTTCGGATACT-3' & This study \\
\hline $16 \mathrm{~S} r \mathrm{RNAR}$ & 5'-AATTCCTTTGAGTTTCAACCTTGCG-3' & This study \\
\hline $\mathrm{TN}-1$ & 5'-GGACCTACCTCATAG-3' & This study \\
\hline IS4351-F & $5^{\prime}$-TCAGAGTGAGAGAAAGGG-3' & This study \\
\hline Tn4351-F & 5'-TGGCACCTTTGTGGTTCTTAC-3' & This study \\
\hline Tn4351-R & 5'-GAGAGACAATGTCCCCCTTTC-3' & This study \\
\hline Erm-F & 5'-GCCCGAAATGTTCAAGTTGT-3' & This study \\
\hline Erm-R & 5'-CTTGACAACCACCCGACTTT-3' & This study \\
\hline M949_RS10475-F & 5'-CCAAACCATATGAACCATCCTGT-3' & This study \\
\hline M949_RS10475-R & 5'-GCATTATCTTCTGACAGGAGAGG-3' & This study \\
\hline M949_RS01035F & 5'-TATAAAGCCTACAATAGC-3' & This study \\
\hline M949_RS01035R & 5'-ATTAATTGAAGAGTTTGC-3' & This study \\
\hline M949_RS01030-F & 5'-TCAATTGCTGAATCCAAACGC-3' & This study \\
\hline M949_RS01030-R & 5'-TTCAGGCATTGTTGTGATGTC-3' & This study \\
\hline RA Idh-F & 5'-AGAGGAGCTTATCGGCATCA-3' & This study \\
\hline RA Idh-R & 5'-CTAGGGCTTCTGCCAATCTG-3' & This study \\
\hline
\end{tabular}

dodecyl sulfate polyacrylamide gel electrophoresis (SDSPAGE) and transferred to a nitrocellulose membrane. After washing with saline sodium citrate, the membrane was immobilized for $2 \mathrm{~h}$ at $80{ }^{\circ} \mathrm{C}$. PCR was performed to amplify the transposon-specific probe representing the 410-bp IS4351 fragment from the plasmid pEP4351 using the primer pair Tn4351-F/Tn4351-R (Table 1). The probe was generated and hybridization was conducted using the DIG DNA labeling and detection kit (Roche Diagnostics USA, Indianapolis, IN, USA), according to the manufacturer's protocol. The plasmid pEP4351 and genomic DNA of the WT strain $\mathrm{CH} 3$ were also subjected to hybridization analysis, for use as the positive and negative controls, respectively.

The nucleotide sequence surrounding the transposon insertion site was determined using inverse PCR, as described elsewhere [24]. Briefly, genomic DNA was digested with the restriction enzyme HindIII and then treated with T4 ligase, which resulted in the formation of circular molecules. Primer pairs specific for Tn 4351 (primers TN-1 and IS4351-F) were used to amplify the sequences adjacent to the insertion site using the LA PCR kit (TaKaRa Biotechnology (Dalian) Co., Ltd.,
Dalian, China). The nucleotide sequence was compared to sequence in the National Center for Biotechnology Information database using the BLASTX program [25].

\section{Determination of the bacterial growth curves}

The growth rates of the WT strain $\mathrm{CH} 3$ and the mutant strain RA1062 were determined and compared. Briefly, each bacterial strain was cultivated in TSB at $37^{\circ} \mathrm{C}$ for $8 \mathrm{~h}$ with shaking. Equal amounts of each bacterial culture were then inoculated into $12-\mathrm{mL}$ of fresh TSB medium at a ratio of $1: 100(\mathrm{v} / \mathrm{v})$ and incubated at $37^{\circ} \mathrm{C}$, with shaking at $200 \mathrm{rpm}$, respectively. The bacterial growth rate was measured by counting the bacterial CFU at 2-h intervals for $16 \mathrm{~h}$.

\section{Characterization of the bacterial phenotype}

The phenotypes of the WT strain $\mathrm{CH} 3$ and its mutant strain RA1062 were determined by crystal violet staining, as previously described [42] with slight modifications. The bacterial cells were grown in TSB at $37{ }^{\circ} \mathrm{C}$ for $8 \mathrm{~h}$, then harvested by centrifugation at $5000 \mathrm{rpm}$ for $5 \mathrm{~min}$, suspended in sterile PBS to a density of $10^{3}$ cells $/ \mathrm{mL}$, plated $(0.1 \mathrm{~mL})$ onto TSA, and incubated at $37^{\circ} \mathrm{C}$ under 
an atmosphere of $5 \% \mathrm{CO}_{2}$ for $36 \mathrm{~h}$. The plates were then gently flooded with $5 \mathrm{~mL}$ of $0.5 \%$ crystal violet solution. After staining for $1 \mathrm{~min}$, the excess stain was removed and the plates were examined immediately.

\section{LPS extraction, silver staining, and Western blot analysis}

Lipopolysaccharide was extracted from WT strain $\mathrm{CH} 3$ and mutant strain RA1062 cells using an LPS extraction Kit (iNtRON Biotechnology, Boca Raton, FL, USA), according to the manufacturer's instruction. Purified LPS was analyzed by SDS-PAGE. Gels were stained with silver to visualize the presence of LPS [26] and then counter stained with Coomassie blue to exclude contaminating proteins.

For Western blot analysis, the purified LPS was separated by SDS-PAGE and then transferred onto nitrocellulose membranes (Millipore, Billerica, MA, USA), which were blocked overnight at $4{ }^{\circ} \mathrm{C}$ in PBS containing 5\% nonfat milk and then washed with PBST. The blots were incubated with anti-CH3 LPS as the primary mAb and then with an IRDYE680CW-conjugated donkey antimouse IgG polyclonal antibody (LI-COR Biosciences, Lincoln, NE, USA) for $1 \mathrm{~h}$. The blots were visualized with an Odyssey two-color infrared imaging system (LI-COR Biosciences).

\section{Serum sensitivity assay}

Bacterial susceptibility to normal duck sera was tested as described elsewhere [27], with slight modifications. Briefly, normal complement-sufficient duck sera (without anti-R. anatipestifer antibody) were collected from 18-old-day healthy Cherry Valley ducks, pooled, and filter-sterilized $(0.22 \mu \mathrm{m})$. Pooled duck sera were diluted to $12.5 \%, 25 \%$, and $50 \%(\mathrm{v} / \mathrm{v})$ in $\mathrm{pH} 7.2$ PBS. Then, $10-\mu \mathrm{L}$ aliquots of bacterial suspension containing $10^{6} \mathrm{CFU}$ in PBS was added to $190 \mu \mathrm{L}$ of serial diluted duck sera, $100 \%$ heat-inactivated serum, or PBS alone, respectively. The reaction mixtures were incubated at $37{ }^{\circ} \mathrm{C}$ under an atmosphere of $5 \% \mathrm{CO}_{2}$ for $30 \mathrm{~min}$. Afterward, the bacterial culture was serial diluted by tenfold and the bacterial count in each sample was calculated by plating onto TSA plates at $37{ }^{\circ} \mathrm{C}$ under an atmosphere of $5 \% \mathrm{CO}_{2}$ for $36 \mathrm{~h}$. The experiment was performed in triplicate.

\section{Adhesion and invasion assays}

Bacterial adhesion and invasion assays were performed using Vero cells (ATCC CCL-81) as described elsewhere [10]. Briefly, Vero cells $\left(10^{5} /\right.$ well) were grown in 24-well tissue culture trays in Dulbecco's modified Eagle medium (DMEM), containing 10\% fetal bovine serum (Biowest, Nuaillé, France). Prior to infection, confluent monolayers of Vero cells were rinsed three times with sterile PBS and then infected with the WT strain $\mathrm{CH} 3$ or the mutant strain RA1062 at a multiplicity of infection of 100 . Infected cells were incubated at $37{ }^{\circ} \mathrm{C}$ under an atmosphere of $5 \% \mathrm{CO}_{2}$ for $1.5 \mathrm{~h}$. Non-adherent bacteria were removed by washing three times with sterile PBS. The cell-adherent bacteria were enumerated following dispersion with PBS-0.1\% trypsin, serial diluted tenfold, and spread onto TSA plates to estimate the number of bacteria (CFU) adhering to the cell monolayers. For the invasion assay, the cell culture, bacterial infection, and plating procedures were performed as described for the adherence assay. After bacterial infection, $1 \mathrm{~mL}$ of DMEM medium containing $100 \mu \mathrm{g} / \mathrm{mL}$ of gentamicin was added to each well and the plate was incubated at $37^{\circ} \mathrm{C}$ under an atmosphere of $5 \% \mathrm{CO}_{2}$ for additional $1 \mathrm{~h}$ to kill extracellular bacteria. All of samples were assayed in triplicate and the assay was conducted independently three times.

\section{Bacterial virulence determination}

The median lethal dose $\left(\mathrm{LD}_{50}\right)$ of the WT strain $\mathrm{CH} 3$ and the mutant strain RA1062 was determined using 18-day-old Cherry Valley ducks as described elsewhere [10]. The ducks were randomly divided into five groups (8 ducks/group), and inoculated intramuscularly with the appropriate bacterial strain at a dose of $10^{6}, 10^{7}, 10^{8}, 10^{9}$, or $10^{10} \mathrm{CFU}$, respectively. Moribund ducks with clinical signs of diarrhoea, pyrexia, anorexia, stunted growth, respiratory signs, neurological abnormalities, or ocular signs were euthanized humanely with an intravenous injection of sodium pentobarbital at a dose of $120 \mathrm{mg} /$ $\mathrm{kg}$ and counted as dead. On post-mortem, a yellow-white exudate and congestion can be seen throughout the body. Ducks were monitored daily for death rate for a period of 7 days post-infection to calculate $\mathrm{LD}_{50}$ value according to the improved Karber's method [28]. The diagnosis was finally confirmed by bacterial isolation from liver, spleen and brain samples of dead ducks.

To evaluate bacterial survival in vivo, 18-day-old Cherry Valley ducks were divided randomly into two groups (6 ducks/group) and injected intramuscularly with $5 \times 10^{8} \mathrm{CFU}$ of the WT strain $\mathrm{CH} 3$ or the mutant strain RA1062. Blood samples were collected at 6, 12, 24,48 , and $72 \mathrm{~h}$ post-infection (hpi) (six ducks per group at each time point), diluted tenfold to appropriate concentrations, and plated in triplicate on TSA for bacterial counting.

\section{Illumina sequencing for RNA-Seq and differential gene expression analyses}

The quantity and quality of total RNA were assessed using the Agilent RNA 6000 Nano Kit and the Agilent 2100 Bioanalyzer (Agilent Technologies, Santa Clara, CA, USA). Total RNA was treated with the Ribo-Zero Magnetic Gold Kit (Epicentre ${ }^{\circledR}$ (an Illumina company), 
Madison, WI, USA) to remove ribosome RNA, then libraries were constructed using the TruSeq RNA Sample Prep Kit v2 (Illumina, Inc., San Diego, CA, USA) in accordance with the manufacturer's instructions. The quality and quantity of the libraries were assessed by two methods: the distribution of the fragment size was checked using the Agilent 2100 bioanalyzer (Agilent DNA 1000 Reagents) and quantified using real-time qPCR (TaqMan Probe). The qualified libraries were amplified on cBot to generate the cluster on the flowcell (TruSeq PE Cluster Kit V3-cBot-HS, Illumina). Then, the amplified flowcell was sequenced via the paired-end method on the HiSeq2000 System (TruSeq SBS KIT-HS $\mathrm{V} 3$, Illumina), with a read length of $90 \mathrm{bp}$, which is the most common sequencing strategy.

The complete libraries were sequenced for 100 cycles on the Illumina HiSeq2000 system as described elsewhere [29]. Image analysis and base calling were performed using Solexa pipeline version 1.8 (Off-Line Base Caller software, version 1.8) [30]. Cleaned reads were aligned to the genome of $R$. anatipestifer strain $\mathrm{CH} 3$ using RNA Sequel software [31]. Transcript levels were calculated as reads per kilobase of cDNA per million fragments mapped. Differentially expressed genes were analyzed using Cufflinks software (version 2.1.1) with significance at a fold change cut-off of 2.0 [32] and considered statistically significant if the fold change was $>2.0$ and false discovery rate of $<0.001$.

\section{Real-time quantitative PCR (qPCR) analysis}

qPCR was performed to confirm the transcriptional levels of differentially expressed genes obtained by RNA-Seq analysis. Gene-specific primers (Table 1) were designed using primer3 online software version 0.4.0 [33]. The expression levels of the L-lactate dehydrogenase encoding gene (ldh) were measured using the primer pair RA ldh-F/RA ldh-R (Table 1) and used as an internal control [34]. Total RNA was isolated from the WT strain $\mathrm{CH} 3$ and the mutant strain RA1062 using TRIzol reagent (Invitrogen Corporation, Carlsbad, CA, USA), according to the manufacturer's instructions. All RNA samples were treated with the TURBO DNA-free kit (Ambion/Life Sciences, Grand Island, NY, USA) to remove DNA contamination. cDNA was synthesized using PrimeScript RT Master Mix (Takara). qPCR was conducted using Go Taq qPCR Master Mix (Promega, Fitchburg, WI, USA) with the following parameters: $95^{\circ} \mathrm{C}$ for $2 \mathrm{~min}, 40$ cycles of $95{ }^{\circ} \mathrm{C}$ for $15 \mathrm{~s}, 55^{\circ} \mathrm{C}$ for $15 \mathrm{~s}$ and $68^{\circ} \mathrm{C}$ for $20 \mathrm{~s}$, followed by one cycle of $95^{\circ} \mathrm{C}$ for $15 \mathrm{~s}, 60^{\circ} \mathrm{C}$ for $15 \mathrm{~s}$ and $95^{\circ} \mathrm{C}$ for $15 \mathrm{~s}$. Reactions were performed in triplicate and run on the Mastercycler ep realplex4 apparatus (Eppendorf AG, Hamburg, Germany). Quantification of transcriptional level was calculated according to the $2^{-\Delta \Delta C t}$ method.

\section{Vaccination and challenge assays}

To determine whether the mutant strain RA1062 conveyed effective cross-protection among different $R$. anatipestifer strains, the inactivated RA1062 and $\mathrm{CH} 3$ vaccines were prepared using the mutant strain RA1062 and the WT strain $\mathrm{CH} 3$, respectively. Briefly, strains RA1062 and $\mathrm{CH} 3$ were cultured separately in TSB at $37{ }^{\circ} \mathrm{C}$ for $10 \mathrm{~h}$ with shaking. The bacterial culture was then adjusted to $10^{10} \mathrm{CFU} / \mathrm{mL}$ and inactivated with $0.4 \%$ (vol/vol) formalin at $37^{\circ} \mathrm{C}$ for $16 \mathrm{~h}$, respectively. The vaccine was made by blending 3 volume inactivated strains (RA1062 or CH3) and 7 volumes of Montanide ISA 70 VG adjuvant (Seppic Shanghai Special Chemical Corporation, Shanghai, China) according to the manufacturer's protocol. Each duck was subcutaneously injected in the neck with $0.3 \mathrm{~mL}$ of the vaccine containing $10^{9} \mathrm{CFU}$ bacterial cells of RA1062 or $\mathrm{CH} 3$ respectively. Cherry Valley ducks were divided randomly into three groups (24 ducks per group). The ducks in group 1 received two subcutaneous injections of the inactivated RA1062 vaccine, at a dose of $10^{9} \mathrm{CFU}$. Each duck in group 2 received two subcutaneous injections of the inactivated $\mathrm{CH} 3$ vaccine, and those in group 3 received two subcutaneous injections of saline in adjuvant for use as controls. At 14 days after the second immunization, eight ducks from each group were challenged with $R$. anatipestifer strain WJ4 (serotype 1), Yb2 (serotype 2), or HXb2 (serotype 10) at $10 \mathrm{LD}_{50}$, respectively. Ducks were monitored daily for clinical symptoms and death until 7 days post-infection. The protection rate was calculated as follows: $[1-$ (no. of dead ducks per group/total no. of ducks per group) $] \times 100$. The experiment was repeated for three times.

\section{Statistical analysis}

All statistical analyses were performed using GraphPad Prism, version 5.0 for Windows software (GraphPad Software Inc., La Jolla, CA, USA). Adhesion and invasion assays, bacterial growth curves, bacterial loads in the blood of ducks, serum sensitivity assays, and RT-qPCR were two tailed, and a $p$-value of $<0.05$ was considered statistically significant. Analysis of variance was used for comparisons of multiple groups.

\section{Results}

\section{Identification of the mutant strain RA1062}

The mutant strain RA1062, which lacked reactivity with the anti-CH3 LPS mAb, was obtained by screening the transposon library using an indirect ELISA and identified by PCR amplification using the primer pairs $16 \mathrm{~S}$ rRNA F/16S rRNA R, Erm-F/Erm-R, and RA1062-F/ RA1062-R. As shown in Figure 1A, a 744-bp fragment of $16 \mathrm{~S}$ rRNA gene was amplified from the WT strain $\mathrm{CH} 3$ (lane 1) and the mutant strain RA 1062 (lane 2), a 678-bp 

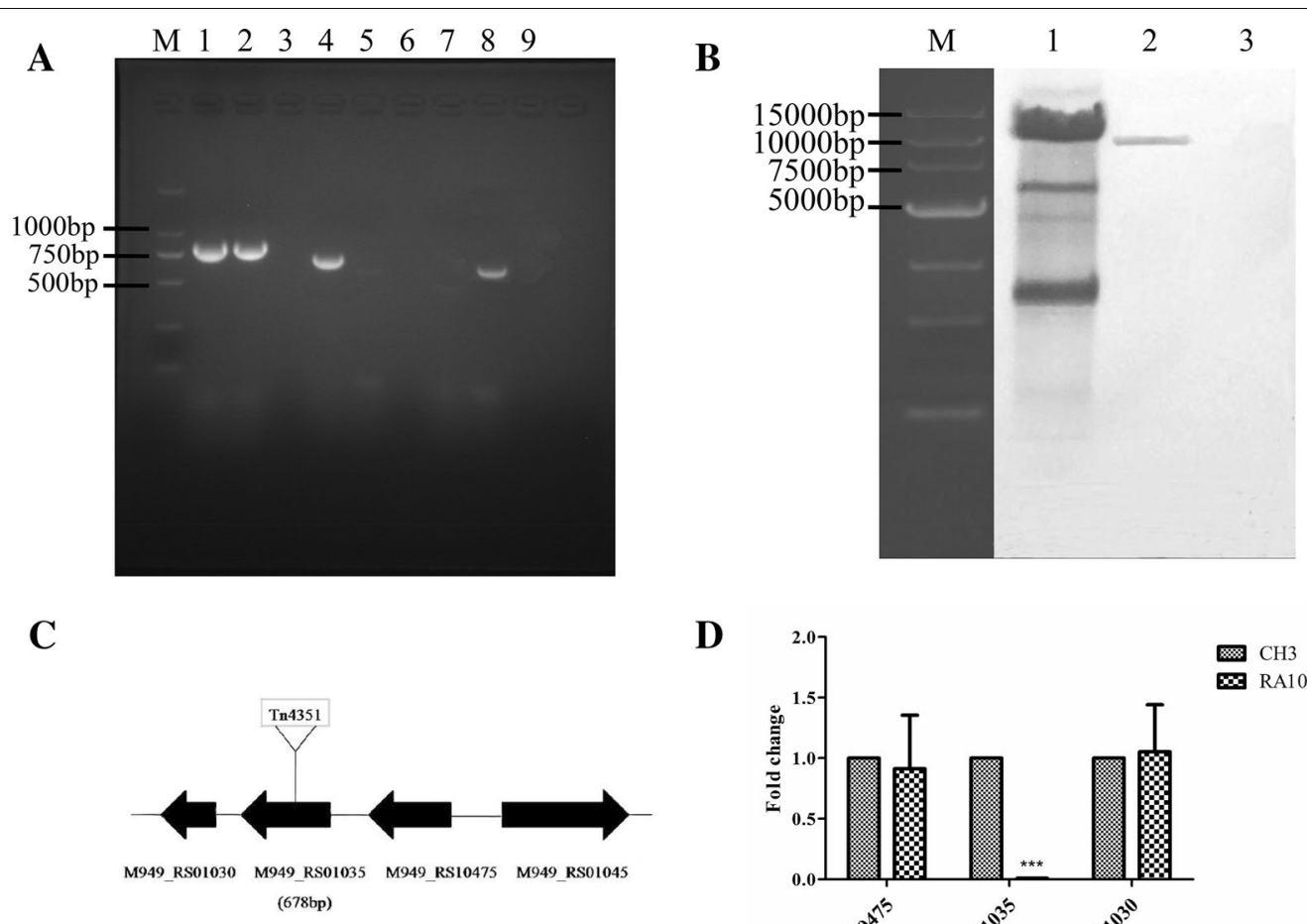

D

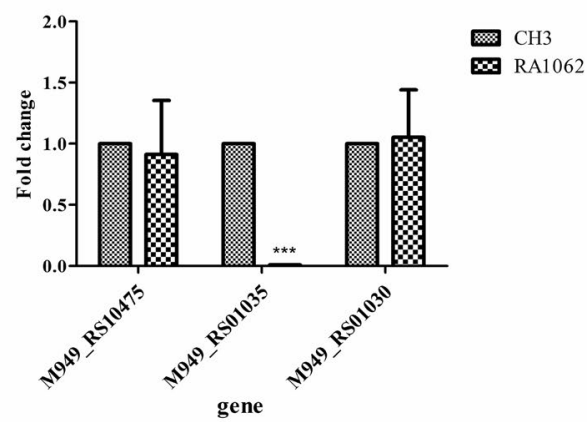

Figure 1 Identification of the mutant strain RA1062. A PCR amplification. M: Takara DL2000 marker; lanes 1-2: R. anatipestifer 16S rRNA was amplified from the WT strain CH3 (lane 1), the mutant strain RA1062 (lane 2), showing a 744-bp fragment of 16S rRNA; lanes 4-5: a 678-bp fragment of M949_RS01035 was amplified from the WT strain CH3 (lane 4), but not the mutant strain RA1062 (lane 5); lanes 7-8: the 644-bp fragment of erm gene was not amplified from the WT strain CH3 (lane 7), but amplified from the mutant strain RA1062 (lane 8); lanes 3, 6 and 9: the avian pathogenic E. coli strain (APEC, CVCC1547), as negative controls. B Southern blot analysis of the transposon Tn4351 insertion. Lane 1, $10 \mu \mathrm{g}$ of pEP4351 digested with Xbal (positive control); Lane 2, $10 \mu \mathrm{g}$ of chromosomal DNA from mutant strain RA1062 digested with Xbal; Lane 3, $10 \mu \mathrm{g}$ of chromosomal DNA from the WT strain $\mathrm{CH} 3$ digested with Xbal (negative control). The digested sample was resolved on a $0.7 \%$ agarose gel and Southern blot analysis was performed using a TnDIG-labeled probe. C Schematic chart of Tn4351 insertion in RA1062 chromosome at 318 bp of the gene, which is 678 nucleotides in length. $\mathbf{D}$ qPCR analysis. The expression of the mRNAs were expressed as fold change and calculated using the comparative $C_{T}\left(2^{-\triangle \Delta C T}\right)$ method. Data were normalized to the housekeeping gene $1 d h$ and expressed as fold changes. The expression of M949_RS01035 in the mutant strain RA1062 was disrupted. However, no change was shown for its upstream M949_RS10475 gene and downstream M949_RS01030 gene. Error bars represent standard deviations from three replicates $\left({ }^{* *} p<0.001\right)$.

fragment of the M949_RS01035 gene was amplified from the WT strain $\mathrm{CH} 3$ (lane 4), but not from the mutant strain RA1062 due to the transposon insertion (lane 5), and a 644-bp fragment of the erm gene (contained in the Tn4351 transposon) was amplified from the mutant strain RA1062 (lane 8), but not from the WT strain CH3 (lane 7). The mutant strain RA1062 was confirmed to contain a single Tn4351 insertion in the chromosomal DNA by Southern blot analysis (Figure 1B, lane 2).

The transposon was inserted at nucleotide position 318 bp of the M949_RS01035 gene, which is 678 nucleotides in length and encodes intramembrane metalloprotease of the CPBP (CAAX proteases and bacteriocin-processing enzymes) family, which consists of 225 amino acids (Figure 1C). BLAST analysis showed that
M949_RS01035 gene exists in $R$. anatipestifer serotype 1 strains $\mathrm{CH} 3$ and $\mathrm{CH}-1$, as well as serotype 10 strain $\mathrm{HXb} 2$ (Additional file 1). qPCR analysis further confirmed that transcription of the M949_RS01035 gene was abolished in the mutant strain RA1062 (Figure 1D). Further investigation showed that transcription of chromosomally upstream M949_RS10475 gene, which encodes a hypothetical protein, and the downstream M949_RS01030 gene, which encodes a "prevent host death" protein, had no significant changes, as compared with the WT strain CH3 (Figure 1D).

\section{Determination of bacterial growth curves}

Bacterial growth curves of the WT strain $\mathrm{CH} 3$ and the mutant strain RA1062 in TSB medium were constructed. 
Compared to that of the WT strain $\mathrm{CH} 3$, the growth rate of the mutant strain RA1062 was similar at the early growth stage, but then significantly decreased at the late growth stage. After $12 \mathrm{~h}$ in TSB, growth of the WT strain $\mathrm{CH} 3$ reached a plateau of $5.12 \times 10^{9} \mathrm{CFU} /$ $\mathrm{mL}$, while the mutant strain RA1062 reached a plateau of $1.99 \times 10^{9} \mathrm{CFU} / \mathrm{mL}$ after $8 \mathrm{~h}$ in TSB. The bacterial numbers of the mutant strain RA1062 at the plateau was about 2.79-fold less than that of the WT strain $\mathrm{CH} 3$ (Figure 2).

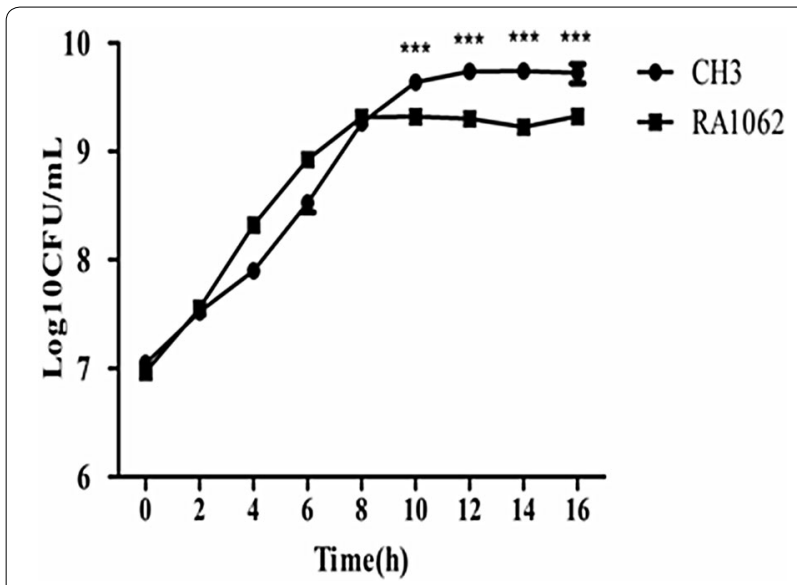

Figure 2 Construction of bacterial growth curves. Strains $\mathrm{CH} 3$ and RA1062 were grown in TSB at $37^{\circ} \mathrm{C}$ with shaking, and the bacterial CFU were measured at 2-h intervals. The experiment was repeated three times and the data are presented as the mean \pm standard deviation. Error bars represent standard deviations. Asterisks indicate statistically significant differences between groups $\left({ }^{* * *} p<0.001\right)$.

\section{Bacterial phenotype characterization by crystal violet staining}

Crystal violet staining was used to characterize the bacterial phenotypes of the WT strain $\mathrm{CH} 3$ and the mutant strain RA1062. The result indicated that the WT strain $\mathrm{CH} 3$ was not stained by crystal violet (Figure $3 \mathrm{~A}$ ), while the mutant strain RA1062 was (Figure 3B), suggesting a change in its phenotype of the mutant strain RA1062.

\section{Analysis of the bacterial LPS by silver staining and Western blot}

LPS was purified from the WT strain $\mathrm{CH} 3$ and the mutant strain RA1062, then subjected to SDS-PAGE followed by silver staining and Western blot analysis. As shown in Figure 4A, LPS purified from the WT strain $\mathrm{CH} 3$ displayed a ladder-like pattern around $70 \mathrm{kDa}$ (lane 2 ), while the ladder-like pattern was deficient in the mutant strain RA1062 LPS (lane 3) in the silver staining. Western blot analysis using the anti-CH3 LPS mAb detected a ladder-like pattern of $\mathrm{O}$-antigen repeats in the $\mathrm{CH} 3$ strain (lane 2), but the pattern was defective in the mutant strain RA 1062 (Figure 4B). These results suggest that the $R$. anatipestifer M949_RS01035 gene is involved in LPS O-antigen biosynthesis.

\section{Adhesion and invasion assays}

To determine the role of the M949_RS01035 gene in bacterial adherence and invasion, we compared bacterial adhesion and invasion abilities of the WT strain $\mathrm{CH} 3$ and the mutant RA1062 on Vero cells. The results showed that the mutant strain RA1062 displayed approximately 21.92-fold enhanced adherence ability (Figure 5A) and
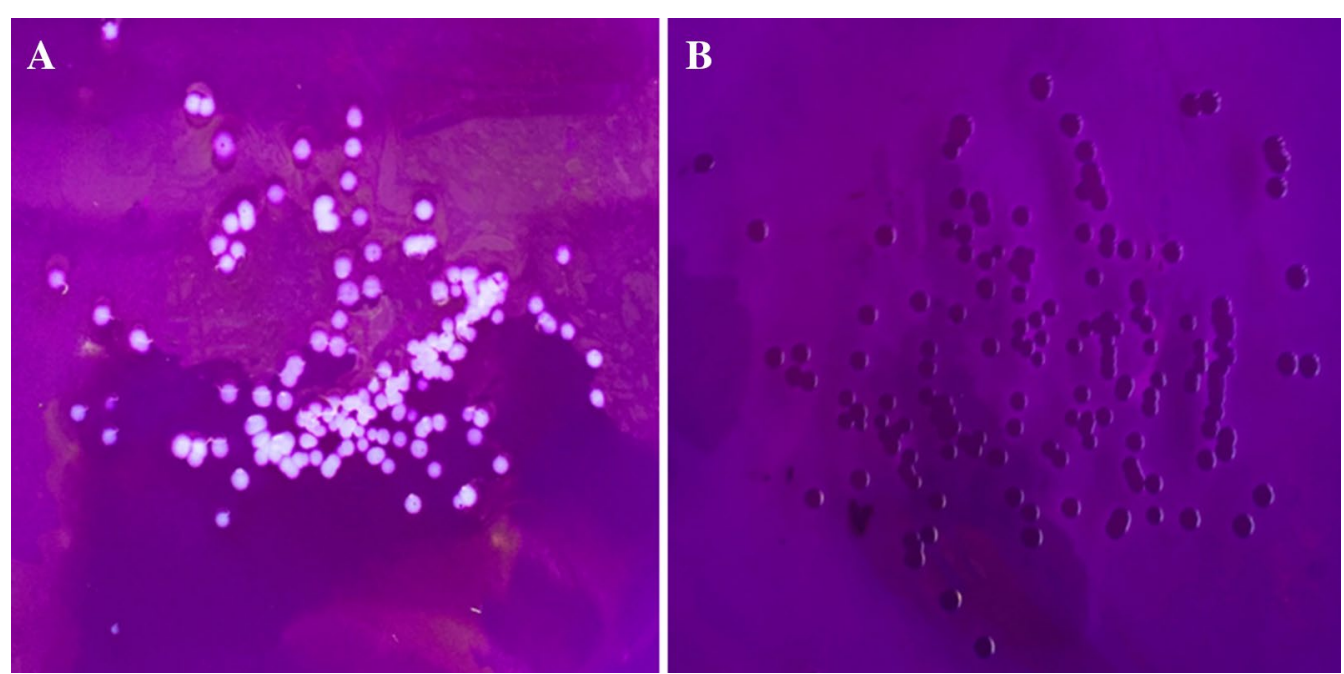

Figure 3 Crystal violet staining. Crystal violet staining was used to differentiate the bacterial phenotypes. A CH3 strain; B RA1062 mutant. Mutant strain RA1062 was stained by crystal violet. 

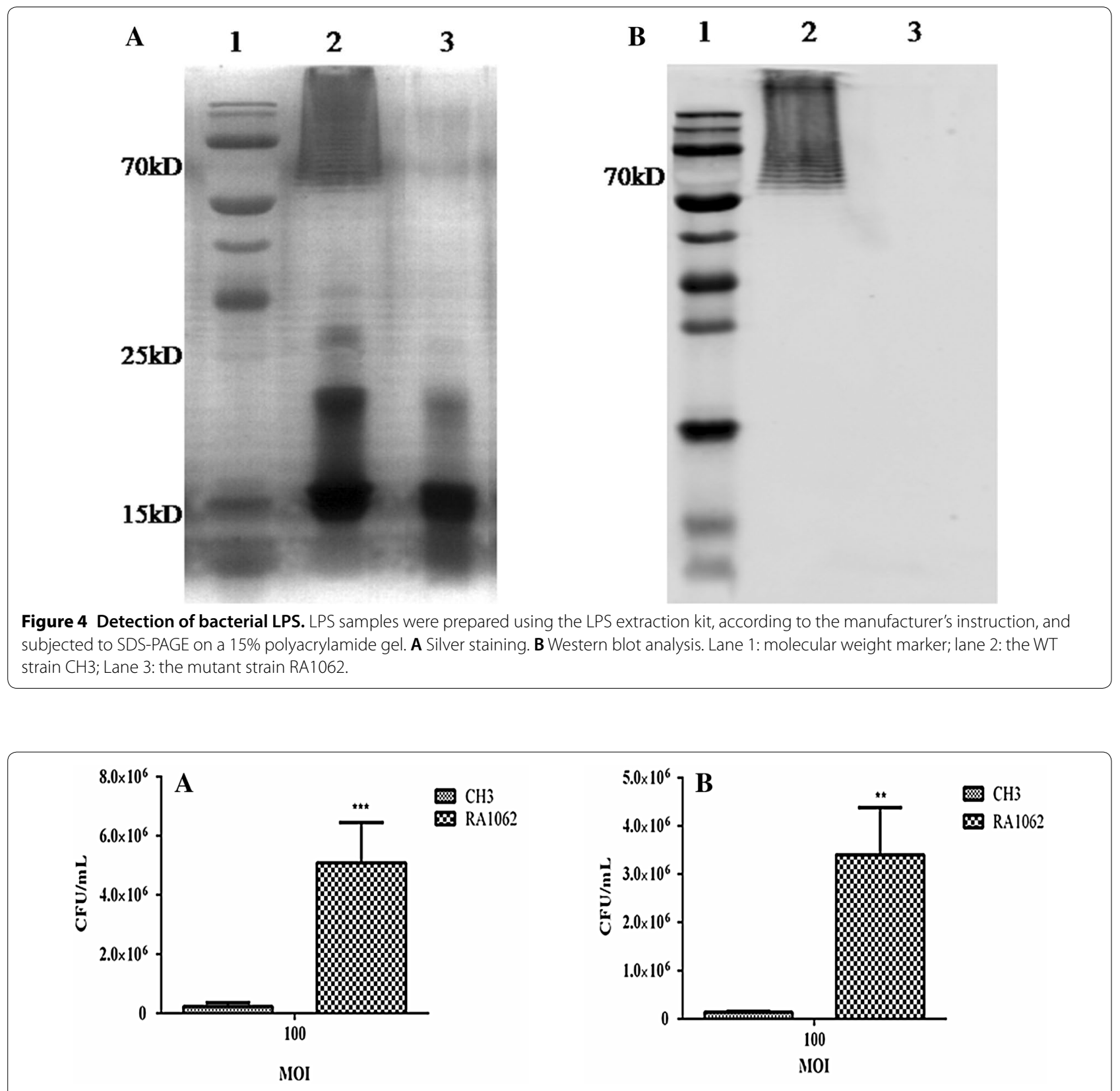

Figure 5 Bacterial adherence and invasion assays. Strains $\mathrm{CH} 3$ and RA1062 were tested on Vero cells. A Adherence assay; B Invasion assay. The data represent the number of bacteria bound to or invaded into Vero cells in each well of a 24-well plate. The error bars represent mean \pm standard deviations from three independent experiments $\left({ }^{* *} p<0.01 ; *^{* *} p<0.001\right)$. The adherence and invasion capacities of the RA1062 mutant were significantly increased in comparison with its WT strain $\mathrm{CH} 3$.

25.18-fold increased invasion capacity (Figure 5B) in comparison with those of the WT strain CH3 $(p<0.001)$.

\section{The mutant strain RA1062 was more sensitive to normal duck sera}

To determine whether the M949_RS01035 gene is involved in serum resistance of the WT strain $\mathrm{CH} 3$, we compared the abilities of the WT strain $\mathrm{CH} 3$ and the mutant strain RA1062 to resist the complementmediated killing. The results showed that $25 \%$ diluted serum was effective in killing the mutant strain RA1062, but not the WT strain $\mathrm{CH} 3$, indicating that the mutant strain RA1062 was more sensitive to normal duck sera than the WT strain $\mathrm{CH} 3$ (Figure 6). 


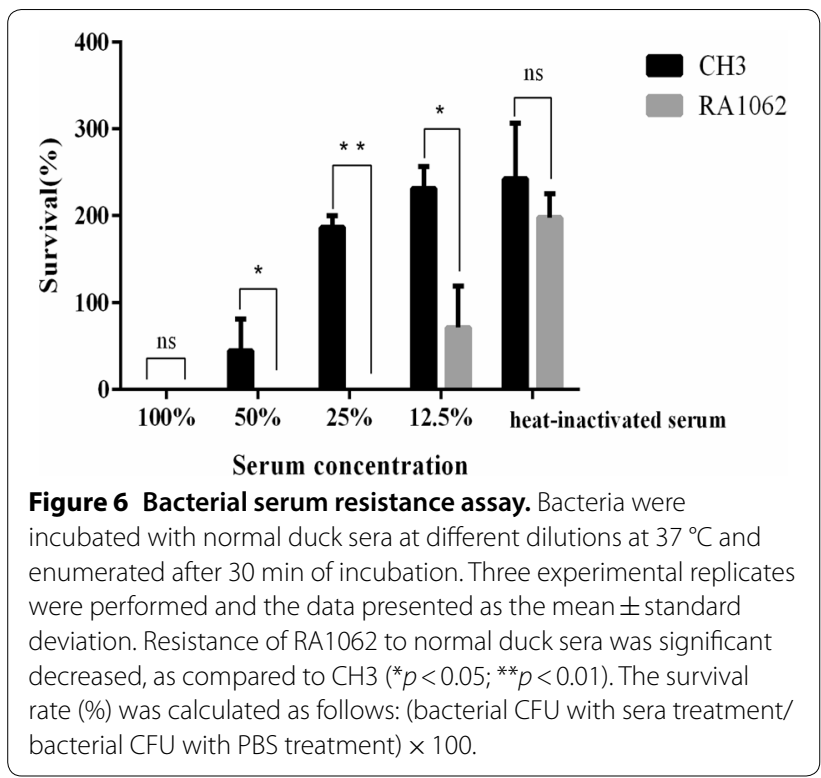

\section{Determination of bacterial virulence}

Bacterial virulence was evaluated based on $\mathrm{LD}_{50}$ determination using 18-day-old Cherry Valley ducks. The $\mathrm{LD}_{50}$ of the mutant strain RA1062 was $2.74 \times 10^{10} \mathrm{CFU}$, which was more than 365 -fold greater attenuated virulence than that of the WT strain $\mathrm{CH} 3\left(7.50 \times 10^{7} \mathrm{CFU}\right)$. In addition, to confirm the role of the M949_RSO1035 gene in systemic invasion and dissemination, bacterial loading in the blood of ducks infected with the WT strain and the mutant strain RA1062 was conducted. As shown in Figure 7, the bacterial loads in the blood of ducks infected with the WT strain $\mathrm{CH} 3$ continued to increase up to $72 \mathrm{hpi}$, while that in the blood of ducks infected with the mutant strain RA1062 decreased from 48 hpi, indicating a significant decrease in comparison with ducks infected with the WT strain $\mathrm{CH} 3$ at 48 and $72 \mathrm{hpi}(p<0.001)$. This experimental result further confirmed the attenuated virulence of the mutant strain RA1062.

\section{Identification of differentially expressed genes}

Strand-specific Illumina RNA-Seq analysis was used to identify differentially expressed genes between the WT strain $\mathrm{CH} 3$ and the mutant strain RA1062. In total, 12 genes were up-regulated and nine were down-regulated in the mutant strain RA1062 in comparison to the WT strain $\mathrm{CH} 3$ (Table 2), which were differentially expressed over fivefold based on RNA-Seq analysis. qPCR further confirmed that the M949_RS07300 and M949_RS04680 genes were up-regulated, and the M949_RSO7580 and M949_RS03025 genes were down-regulated by more than fivefold at the transcriptional level. The proteins encoded by the M949_RS07300, M949_RS04680, and

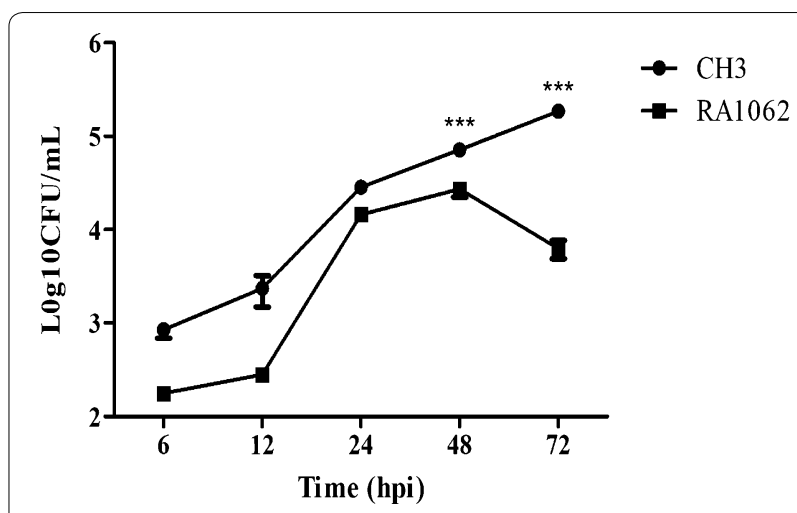

Figure 7 Determination of bacterial virulence. Bacterial loads in the blood of ducks infected with $\mathrm{CH} 3$ or RA1062 at 6, 12, 24, 48, and $72 \mathrm{hpi}$. Three experimental replicates were performed and the data presented in the figure were from one representative experiment.

The error bars represent means \pm standard deviations from six ducks. Asterisks indicate statistically significant differences between groups $\left({ }^{* * *} p<0.001\right)$.

M949_RS03025 genes were annotated as TonB-dependent receptors. The coding product of the M949_RSO7580 gene was annotated as the polysaccharide biosynthesis protein CapD, which is responsible for bacterial capsule polysaccharide biosynthesis. These results indicated that the M949_RS01035 gene regulated several genes responsible for bacterial polysaccharide biosynthesis.

\section{Cross-protection experiment}

To investigate the cross-protection against $R$. anatipestifer serotypes 1, 2, and 10, the RA1062-vaccinated ducks were challenged with virulent $R$. anatipestifer strains WJ4 (serotype 1), Yb2 (serotype 2), and HXb2 (serotype 10) at $10 \mathrm{LD}_{50}$, respectively. Protection from challenge with strains WJ4, Yb2, and HXb2 was greater in RA1062-vaccinated ducks than those vaccinated with $\mathrm{CH} 3$. In contrast, all non-vaccinated ducks were dead within 7 days post-challenge. Three experimental replicates showed similar cross-protection results (Table 3). These results indicated that RA1062 provided cross-protection against challenge with $R$. anatipestifer serotypes 1, 2, and 10, which further confirmed its altered antigenicity.

\section{Discussion}

This study was initially designed to discover genes of $R$. anatipestifer strain $\mathrm{CH} 3$ involved in LPS biosynthesis and to explore potential use of the mutant for development of a cross-protective vaccine. The mutant strain RA1062 was obtained by screening the random $\operatorname{Tn} 4351$ transposon mutant library with an indirect ELISA, which lacked reactivity with the anti-CH3 LPS mAb. Further investigations revealed that the phenotype of the 
Table 2 qPCR verification of differentially expressed genes in the mutant strain RA1062

\begin{tabular}{lll}
\hline Gene locus $^{\text {a }}$ & Description of genes & Fold-change \\
\hline M949_RS07300 & TonB-dependent receptor & 7.80 \\
M949_RS04680 & TonB-dependent receptor & 7.57 \\
M949_RS02830 & TonB-dependent receptor & 4.58 \\
M949_RS02835 & Hypothetical protein & 3.37 \\
M949_RS09405 & Transcriptional regulator & 2.34 \\
M949_RS10455 & DNA-binding protein & 2.21 \\
M949_RS10515 & Hypothetical protein & 1.85 \\
M949_RS02445 & Leucine-rich repeat-containing protein & 1.73 \\
M949_RS10510 & S41 family peptidase & 1.50 \\
M949_RS08410 & Hypothetical protein & 1.08 \\
M949_RS06030 & Hypothetical protein & 0.93 \\
M949_RS02320 & Hypothetical protein & 0.92 \\
M949_RS05620 & Hypothetical protein & 0.90 \\
M949_RS02480 & Hypothetical protein & 0.86 \\
M949_RS02475 & Hypothetical protein & 0.83 \\
M949_RS04495 & Phosphate sodium symporter & 0.68 \\
M949_RS10460 & Hypothetical protein & 0.65 \\
M949_RS10465 & Hypothetical protein & 0.53 \\
M949_RS05615 & DNA-binding protein & 0.42 \\
M949_RS03025 & TonB-dependent receptor & 0.16 \\
M949_RS07580 & Polysaccharide biosynthesis protein & 0.03 \\
& CapD & \\
\hline
\end{tabular}

${ }^{a}$ Based on the genome of $R$. anatipestifer strain $\mathrm{CH} 3$ (Accession Number: CP006649).

mutant strain was altered with a decreased growth rate in TSB, increased sensitivity to normal duck serum, and increased bacterial adhesion and invasion capacities on Vero cells, as compared to the WT strain CH3. Sequence analysis revealed that the transposon was inserted into the M949_RSO1035 gene of strain CH3 at $318 \mathrm{bp}$.
The protein encoded by the M949_RSO1035 gene is annotated as an intramembrane metalloprotease of the CPBP (CAAX proteases and bacteriocin-processing enzymes) family, which exhibited a high degree of similarity with the Abi family proteins of Lactobacillus plantarum. The members of the Abi protein family are reportedly involved in bacteriocin self-immunity in streptococci [35]. A BLAST search indicated that the M949_RS01035 gene exists in $R$. anatipestifer serotypes 1 strains $\mathrm{CH} 3$ and $\mathrm{CH}-1$, as well as serotype 10 strain HXb2. Silver staining indicated a marked deficiency of the ladder-like pattern in RA1062 mutant LPS, as compared to CH3 LPS. Western-blot analysis further confirmed that the modified LPS was less reactive with the anti-CH3 LPS mAb, suggesting that the M949_RS01035 gene is associated with the LPS O-antigen biosynthesis.

It has been reported that the $\mathrm{O}$-antigen side-chains are main components of LPS molecules of E. coli and Salmonella typhimurium involved in serum resistance by virtue of their anti-complement activities [36]. In the present study, the mutant strain RA1062 exhibited increased sensitivity to normal duck serum. Therefore, we speculated that the higher sensitivity of the mutant strain RA1062 to normal duck serum may due to a defect to the $\mathrm{O}$-antigen, leading to easier bacteria killing by serum. It is also well established that the $\mathrm{O}$-antigen plays a significant role in bacterial virulence [37]. Animal experiments further demonstrated that the virulence of mutant strain RA1062 was significantly decreased, as compared to the WT strain $\mathrm{CH}$. These experimental data demonstrate that bacterial $\mathrm{O}$-antigen is not only involved in bacterial resistance to complement-mediated killing, but also an important virulence factor. It is established that bacterial adherence to the cell surface is the first step in the pathogenesis of microbial infections and functions as a

Table 3 Cross-protection experiment

\begin{tabular}{lllll}
\hline Immunization & Challenge strains ${ }^{\mathbf{a}}$ & Protection rate (\%) & $\begin{array}{l}\text { Geomean of three } \\
\text { protection rates (\%) }\end{array}$ & $\begin{array}{l}\text { SD of three } \\
\text { protection } \\
\text { rates }\end{array}$ \\
& & & 0.00 \\
Inactivated RA1062 vaccine & WJ4 & $100.0 ; 100.0 ; 100.0$ & 100.00 & 7.95 \\
& Yb2 & $87.5 ; 75.0 ; 75.0$ & 100.00 & 0.00 \\
Inactivated CH3 vaccine & HXb2 & $100.0 ; 100.0 ; 100.0$ & 95.65 & 7.22 \\
& WJ4 & $87.5 ; 100.0 ; 100.0$ & 25.00 & 0.00 \\
Non-vaccinated & HXb2 & $25.0 ; 25.0 ; 25.0$ & 50.00 & 0.00 \\
& WJ4 & $50.0 ; 50.0 ; 50.0$ & 0.00 & 0.00 \\
& Yb2 & $0 ; 0 ; 0$ & 0.00 & 0.00 \\
\hline
\end{tabular}

\footnotetext{
${ }^{a}$ Challenge dose was $10 \mathrm{LD}_{50}$ for each strain.

b The protection rate was calculated as follows: [1 - (no. of dead ducks per group/total no. of ducks per group)] $\times 100$. The protection rates for three experimental repeats were shown in the table and separated with semicolon.
} 
critical determinant in colonization [10]. In this study, we found that both adherence and invasion capacities of the mutant strain RA1062 to Vero cells were significantly increased, as compared to those of the WT strain $\mathrm{CH} 3$. This phenomenon is consistent with rough mutants of Brucella abortus, which are taken up in greater numbers by macrophages than the smooth parental strains [38]. The enhanced ability of the mutant strain RA1062 to adhere to and invade Vero cells may also be dependent on the rough LPS phenotype, which employs different adherence and invasion mechanisms, as described for B. abortus [39].

Various antibiotics are currently used to prevent and control $R$. anatipestifer infection in ducks. However, the emergence of drug-resistant and multi-drug resistant strains due to the overuse of antibiotics has become a major barrier in $R$. anatipestifer treatment $[2,40]$. Therefore, immunization of ducks with vaccine provides a valuable alternative to the use of antibiotics. Our study showed that ducks immunized with the mutant strain RA1062 were protected from challenge with $R$. anatipestifer strains WJ4 (serotype 1), Yb2 (serotype 2), and HXb2 (serotype 10 ) at $\geq 8 / 8,6 / 8$ and $8 / 8$, respectively, suggesting that the RA1062 strain is an effective crossprotective vaccine candidate. A previous study reported that conserved LPS epitope(s) exist among different species and genera of non-enteric, Gram-negative, human pathogens [41]. The ability of the mutant strain RA1062 to provide broad cross-protection may be due to the deficiency of LPS O-antigen, which leads to the presence of some conserved LPS epitopes. Another possibility is that some cross-immunogenic components of the $R$. anatipestifer outer membrane, such as outer membrane proteins, are exposed at the bacterial surface of the mutant strain RA1062. However, based on current experiments, the mechanism of the cross-protection induced by the mutant strain RA1062 vaccination remains unclear, thus further work is needed to clarify the nature of the cross-protection.

RNA-Seq has rapidly become the method of choice for the study of differential gene expression, as it enables the investigation and comparison of gene expression levels at unprecedented resolution [42]. In our current RNASeq study, we found that 12 genes were up-regulated and nine were down-regulated by over fivefold in the mutant strain RA1062. qPCR verification further confirmed that two genes were up-regulated and two were down-regulated by over 5 -fold. The proteins encoded by two up-regulated genes (M949_RSO7300 and M949_RS04680) and one down-regulated gene (M949_RS03025) are TonBdependent receptors. TonB-dependent receptors are members of a family of beta-barrel proteins located on the outer membrane of Gram-negative bacteria, which are known to be mainly involved in iron or vitamin B12 uptake [43]. The crystallographic structures of two TonBdependent receptors (FhuA and FepA) have recently been determined [44]. A recent study has identified the TonBdependent receptor TbdR1 in $R$. anatipestifer strain $\mathrm{CH} 3$, which is a cross-immunogenic protein among strains with different serotypes [45]. Further investigation demonstrated that TbdR1 had a crucial role in the process of iron acquisition and complicated pathogenesis of $R$. anatipestifer strain CH3 [46]. However, how these TonBdependent receptors are regulated by the M949_RS01035 gene remains unknown, thus further studies are needed to elucidate the nature of this phenomenon. The M949 RS07580 gene, which encodes the polysaccharide biosynthesis protein $\mathrm{CapD}$, was significantly down-regulated by over 30 -fold, which was consistent with the findings of our previous study [19]. It has been established that the polysaccharide biosynthesis protein CapD is a novel pathogenicity-associated determinant that is involved in the serum-resistance ability of $H$. parasuis and $E$. faecium $[47,48]$. Protein sequence analysis indicated that there is a NAD-binding domain in the polysaccharide biosynthesis protein CapD, which is reportedly associated with LPS O-antigen biosynthesis [49]. Additionally, the polysaccharide biosynthesis protein CapD is responsible for the biosynthesis of type 1 capsular polysaccharides in Staphylococcus aureus [50]. Previous work has demonstrated that Group 1 and 4 capsules are related to LPS O-antigens [51]. Based on our current knowledge, we speculated that the loss of the LPS O-antigen in the mutant strain RA1062 may be associated with the downregulation of the M949_RS07580 gene, although further investigations are needed to elucidate the underlying mechanism.

In conclusion, we demonstrated that the M949. RSO1035 gene is involved in bacterial phenotype, virulence, and gene regulation in $R$. anatipestifer. The mutant strain RA1062 could be used as a novel cross-protective vaccine candidate for further vaccine development.

\section{Additional file}

Additional file 1. Sequence analysis of M949_RS01035 gene in $R$. anatipestifer.

\section{Abbreviations \\ LPS: lipopolysaccharide; mAb: monoclonal antibody; ELISA: enzyme-linked immunosorbent assay; PCR: polymerase chain reaction; CFU: colony forming unit; SDS-PAGE: sodium dodecyl sulfate polyacrylamide gel electrophoresis; $\mathrm{LD}_{50}$ : median lethal doses.}

Competing interests

The authors declare that they have no competing interests. 


\section{Authors' contributions}

SY planned the experiments. YD, GY, and XW conducted the experiments. SW, TL, MT, JQ, CD, and SY analyzed and discussed the experimental results. YD and SY wrote the manuscript. All authors read and approved the final manuscript.

\section{Acknowledgements}

We thank Ms. Yingfang Lv for supporting the animal experiments. Funding

This work was supported by the National Key Research and Development Program of China (No. 2016YFD0500805), the Shanghai Key Project on Agricultural Development through Science and Technology (2016HNG4-1) and Co-innovation of Science and Technology Innovation Project in Chinese Academy of Agricultural Sciences (CAAS-XTCX2016011-04-8).

\section{Author details}

1 Shanghai Veterinary Research Institute, Chinese Academy of Agricultural Sciences (CAAS), Shanghai, China. ${ }^{2}$ Jiangsu Co-innovation Center for Prevention and Control of Important Animal Infectious Diseases and Zoonosis, Yangzhou, People's Republic of China.

\section{Publisher's Note}

Springer Nature remains neutral with regard to jurisdictional claims in published maps and institutional affiliations.

Received: 3 July 2018 Accepted: 3 September 2018 Published online: 17 September 2018

\section{References}

1. Segers P, Mannheim W, Vancanneyt M, De Brandt K, Hinz KH, Kersters K, Vandamme P (1993) Riemerella anatipestifer gen. nov., comb. nov., the causative agent of septicemia anserum exsudativa, and its phylogenetic affiliation within the Flavobacterium-Cytophaga rRNA homology group. Int J Syst Bacteriol 43:768-776

2. Sun N, Liu J-H, Yang F, Lin D-C, Li G-H, Chen Z-L, Zeng Z-L (2012) Molecular characterization of the antimicrobial resistance of Riemerella anatipestifer isolated from ducks. Vet Microbiol 158:376-383

3. Sandhu T (2008) Riemerella anatipestifer infection. In: Saif YM, Fadly AM, Glisson JR, McDougald LR, Nolan LK, Swane DE (eds) Diseases of poultry, $12^{\text {th }}$ edn. Blackwell Publishing Ltd, Hoboken

4. Pathanasophon P, Phuektes P, Tanticharoenyos T, Narongsak W, Sawada T (2002) A potential new serotype of Riemerella anatipestifer isolated from ducks in Thailand. Avian Pathol 31:267-270

5. Pathanasophon P, Sawada T, Tanticharoenyos T (1995) New serotypes of Riemerella anatipestifer isolated from ducks in Thailand. Avian Pathol 24:195-199

6. Hu Q, Han X, Zhou X, Ding S, Ding C, Yu S (2010) Characterization of biofilm formation by Riemerella anatipestifer. Vet Microbiol 144:429-436

7. Han X, Hu Q, Ding S, Chen W, Ding C, He L, Wang X, Ding J, Yu S (2012) Identification and immunological characteristics of chaperonin GroEL in Riemerella anatipestifer. Appl Microbiol Biotechnol 93:1197-1205

8. Haiwen L (2013) Development and evaluation of a trivalent Riemerella anatipestifer-inactivated vaccine. Clin Vaccine Immunol 5:691-697

9. Chang CF, Hung PE, Chang YF (1998) Molecular characterization of a plasmid isolated from Riemerella anatipestifer. Avian Pathol 27:339-345

10. Hu Q, Han X, Zhou X, Ding C, Zhu Y, Yu S (2011) OmpA is a virulence factor of Riemerella anatipestifer. Vet Microbiol 150:278-283

11. Murray GL, Attridge SR, Morona R (2003) Regulation of Salmonella typhimurium lipopolysaccharide $\mathrm{O}$ antigen chain length is required for virulence; identification of FepE as a second Wzz. Mol Microbiol 47:1395-1406

12. Murray GL, Attridge SR, Morona R (2006) Altering the length of the lipopolysaccharide $\mathrm{O}$ antigen has an impact on the interaction of Salmonella enterica serovar typhimurium with macrophages and complement. J Bacteriol 188:2735-2739

13. Duerr CU, Zenk SF, Chassin C, Pott J, Gutle D, Hensel M, Hornef MW (2009) O-antigen delays lipopolysaccharide recognition and impairs antibacterial host defense in murine intestinal epithelial cells. PLoS Pathog 5:e1000567

14. Saldias MS, Ortega X, Valvano MA (2009) Burkholderia cenocepacia O antigen lipopolysaccharide prevents phagocytosis by macrophages and adhesion to epithelial cells. J Med Microbiol 58:1542-1548

15. Levine MM, Kotloff KL, Barry EM, Pasetti MF, Sztein MB (2007) Clinical trials of Shigella vaccines: two steps forward and one step back on a long, hard road. Nat Rev Microbiol 5:540-553

16. Austin EA, Graves JF, Hite LA, Parker CT, Schnaitman CA (1990) Genetic analysis of lipopolysaccharide core biosynthesis by Escherichia coli K-12: insertion mutagenesis of the rfa locus. J Bacteriol 172:5312-5325

17. Wang X, Quinn PJ (2010) Lipopolysaccharide: biosynthetic pathway and structure modification. Prog Lipid Res 49:97-107

18. Zou J, Wang X, Ding C, Tian M, Han X, Wang S, Yu S (2015) Characterization and cross-protection evaluation of M949_1603 gene deletion Riemerella anatipestifer mutant RA-M1. Appl Microbiol Biotechnol 99:10107-10116

19. Dou Y, Wang X, Yu G, Wang S, Tian M, Qi J, Li T, Ding C, Yu S (2017) Disruption of the M949_RS01915 gene changed the bacterial lipopolysaccharide pattern, pathogenicity and gene expression of Riemerella anatipestifer. Vet Res 48:6

20. Yu G, Wang X, Dou Y, Wang S, Tian M, Qi J, Li T, Ding C, Wu Y, Yu S (2016) Riemerella anatipestifer M949_1360 gene functions on the lipopolysaccharide biosynthesis and bacterial virulence. PLoS One 11:e0160708

21. Zou J, Wang X, Tian M, Cao S, Hou W, Wang S, Han X, Ding C, Yu S (2015) The M949_1556 gene plays a role on the bacterial antigenicity and pathogenicity of Riemerella anatipestifer. Vet Microbiol 177:193-200

22. Wang X, Ding C, Wang S, Han X, Hou W, Yue J, Zou J, Yu S (2014) The AS87_04050 gene is involved in bacterial lipopolysaccharide biosynthesis and pathogenicity of Riemerella anatipestifer. PLOS One 9:e109962

23. Hu Q, Zhu Y, Tu J, Yin Y, Wang X, Han X, Ding C, Zhang B, Yu S (2012) Identification of the genes involved in Riemerella anatipestifer biofilm formation by random transposon mutagenesis. PLoS One 7:e39805

24. Alvarez B, Secades P, Prieto M, McBride MJ, Guijarro JA (2006) A mutation in Flavobacterium psychrophilum tlpB inhibits gliding motility and induces biofilm formation. Appl Environ Microbiol 72:4044-4053

25. Basic Local Alignment Search Tool. https://blast.ncbi.nlm.nih.gov/Blast .cgi. Accessed 5 July 2016.

26. Tsai CM, Frasch CE (1982) A sensitive silver stain for detecting lipopolysaccharides in polyacrylamide gels. Anal Biochem 119:115-119

27. McQuillen DP, Gulati S, Rice PA (1994) Complement-mediated bacterial killing assays. Methods Enzymol 236:137-147

28. Reed $\amalg$, Muench $H$ (1938) A simple method of estimating fifty per cent endpoints. Am J Epidemiol 27:493-497

29. Wang X, Yue J, Ding C, Wang S, Liu B, Tian M, Yu S (2016) Deletion of AS87_03730 gene changed the bacterial virulence and gene expression of Riemerella anatipestifer. Sci Rep 6:22438

30. Whiteford N, Skelly T, Curtis C, Ritchie ME, Lohr A, Zaranek AW, Abnizova I, Brown C (2009) Swift: primary data analysis for the Illumina Solexa sequencing platform. Bioinformatics 25:2194-2199

31. Wilson GW, Stein LD (2015) RNASequel: accurate and repeat tolerant realignment of RNA-seq reads. Nucleic Acids Res 43:e122

32. Trapnell C, Williams BA, Pertea G, Mortazavi A, Kwan G, van Baren MJ, Salzberg SL, Wold BJ, Pachter $L$ (2010) Transcript assembly and quantification by RNA-Seq reveals unannotated transcripts and isoform switching during cell differentiation. Nat Biotechnol 28:511-515

33. Primer 3 online software version 0.4.0. http://bioinfo.ut.ee/primer3-0.4.0/. Accessed 8 Sept 2016.

34. Huggett J, Dheda K, Bustin S, Zumla A (2005) Real-time RT-PCR normalisation; strategies and considerations. Genes Immun 6:279-284

35. Kjos M, Snipen L, Salehian Z, Nes IF, Diep DB (2010) The abi proteins and their involvement in bacteriocin self-immunity. J Bacteriol 192:2068-2076

36. Tomas JM, Ciurana B, Benedi VJ, Juarez A (1988) Role of lipopolysaccharide and complement in susceptibility of Escherichia coli and Salmonella typhimurium to non-immune serum. J Gen Microbiol 134:1009-1016

37. Sarkar S, Ulett GC, Totsika M, Phan M-D, Schembri MA (2014) Role of capsule and $\mathrm{O}$ antigen in the virulence of uropathogenic Escherichia coli. PLoS One 9:e94786

38. Pei J, Turse JE, Wu Q, Ficht TA (2006) Brucella abortus rough mutants induce macrophage oncosis that requires bacterial protein synthesis and direct interaction with the macrophage. Infect Immun 74:2667-2675 
39. Zhang M, Han X, Liu H, Tian M, Ding C, Song J, Sun X, Liu Z, Yu S (2013) Inactivation of the ABC transporter ATPase gene in Brucella abortus strain 2308 attenuated the virulence of the bacteria. Vet Microbiol 164:322-329

40. Chen Y-P, Lee S-H, Chou C-H, Tsai H-J (2012) Detection of florfenicol resistance genes in Riemerella anatipestifer isolated from ducks and geese. Vet Microbiol 154:325-331

41. Campagnari AA, Spinola SM, Lesse AJ, Kwaik YA, Mandrell RE, Apicella MA (1990) Lipooligosaccharide epitopes shared among Gram-negative nonenteric mucosal pathogens. Microb Pathog 8:353-362

42. Finotello F, Di Camillo B (2015) Measuring differential gene expression with RNA-seq: challenges and strategies for data analysis. Brief Funct Genomics 14:130-142

43. Blanvillain S, Meyer D, Boulanger A, Lautier M, Guynet C, Denancé N, Vasse J, Lauber E, Arlat M (2007) Plant carbohydrate scavenging through TonB-dependent receptors: a feature shared by phytopathogenic and aquatic bacteria. PLoS One 2:e224

44. Ferguson AD, Deisenhofer J (2002) TonB-dependent receptors - structural perspectives. Biochim Biophys Acta 1565:318-332

45. Hu Q, Ding C, Tu J, Wang X, Han X, Duan Y, Yu S (2012) Immunoproteomics analysis of whole cell bacterial proteins of Riemerella anatipestifer. Vet Microbiol 157:428-438
46. Lu F, Miao S, Tu J, Ni X, Xing L, Yu H, Pan L, Hu Q (2013) The role of TonBdependent receptor TbdR1 in Riemerella anatipestifer in iron acquisition and virulence. Vet Microbiol 167:713-718

47. Ali L, Spiess M, Wobser D, Rodriguez M, Blum HE, Sakınç T (2016) Identification and functional characterization of the putative polysaccharide biosynthesis protein (CapD) of Enterococcus faecium U0317. Infect Genet Evol 37:215-224

48. Wang X, Xu X, Wu Y, Li L, Cao R, Cai X, Chen H (2013) Polysaccharide biosynthesis protein $\mathrm{CapD}$ is a novel pathogenicity-associated determinant of Haemophilus parasuis involved in serum-resistance ability. Vet Microbiol 164:184-189

49. Fallarino A, Mavrangelos C, Stroeher UH, Manning PA (1997) Identification of additional genes required for O-antigen biosynthesis in Vibrio cholerae O1. J Bacteriol 179:2147-2153

50. Lin WS, Cunneen T, Lee CY (1994) Sequence analysis and molecular characterization of genes required for the biosynthesis of type 1 capsular polysaccharide in Staphylococcus aureus. J Bacteriol 176:7005-7016

51. Whitfield C (2006) Biosynthesis and assembly of capsular polysaccharides in Escherichia coli. Annu Rev Biochem 75:39-68
Ready to submit your research? Choose BMC and benefit from:

- fast, convenient online submission

- thorough peer review by experienced researchers in your field

- rapid publication on acceptance

- support for research data, including large and complex data types

- gold Open Access which fosters wider collaboration and increased citations

- maximum visibility for your research: over 100M website views per year

At BMC, research is always in progress.

Learn more biomedcentral.com/submissions 